\title{
Prevailing practices in airway management: a prospective single-centre observational study of endotracheal intubation
}

Geraldine Pei Chin $\underline{\text { Cheong }}{ }^{1}$, MBBS, MMed, Anusha $\underline{K a n n a n}^{1}$, MBBS, FCAl, Kwong Fah $\underline{K o h}^{1}$, MBBS, MMed, Kumaresh Venkatesan ${ }^{1}$, FRCA, FFICM, Edwin Seet ${ }^{1}$, MBBS, MMed

\begin{abstract}
INTRODUCTION Airway management during anaesthesia has potential difficulties and risks. We aimed to investigate the utility of routine airway assessment for predicting difficult tracheal intubation, review the prevailing practice of videolaryngoscope use amongst anaesthetists in a teaching hospital and determine the incidence of intraoperative and postoperative airway-related complications.

METHODS A prospective observational study of 1,654 patients undergoing general anaesthesia with endotracheal intubation over a seven-month period was performed. Data regarding airway and anaesthetic management was collected and analysed.

RESULTS Videolaryngoscopes were used as the first-choice equipment in $60.5 \%$ of the cohort. The incidence of difficult intubation was $2.1 \%$, of which $45.7 \%$ of cases were unanticipated. The sensitivity of airway assessment was $54.3 \%$, with a positive predictive value of $8.1 \%$. When difficult intubation was anticipated, more videolaryngoscopes were used as the first equipment of choice compared to the Macintosh laryngoscope $(p<0.001)$. In the Macintosh group, more patients required a change of airway equipment $(p=0.015)$, but the number of intubation attempts was similar $(p=0.293)$. The incidence of intraoperative $(p=0.920)$ and postoperative complications $(p=0.380)$ were similar in both groups.

CONCLUSION Using the current predictors of difficult intubation, half of the difficult airways we encountered were unanticipated. Videolaryngoscopes were preferred when difficulty was anticipated and were also used in routine tracheal intubation.
\end{abstract}

Keywords: airway management, prediction of difficult intubation, unanticipated difficult intubation, videolaryngoscope

\section{INTRODUCTION}

Airway management is deemed an essential skill for all anaesthetists, but is not without potential difficulties and risks. The large National Audit Project undertaken in the United Kingdom uncovered major findings categorised under important clinical themes such as inadequate airway assessment and poor airway management planning, which led to complications and adverse airway outcomes. ${ }^{(1)}$ The American Society of Anesthesiologists Closed Claims analysis found that approximately $6 \%$ of all claims were related to airway injury and more frequently associated with difficult intubation. (2) The incidence of dental injury in airway management was found to be higher in patients with difficult intubation. ${ }^{(3)}$

The practice of endotracheal intubation has evolved over the last decade with the introduction of videolaryngoscopes and other forms of indirect laryngoscopy. ${ }^{(4)}$ No single device has been shown to be superior. However, by providing improved visualisation of the vocal cords, videolaryngoscopes have made the practice of laryngoscopy easier compared with conventional standard laryngoscopes. ${ }^{(5)}$ Studies have proposed using a videolaryngoscope as the first equipment of choice when intubating obese patients ${ }^{(6)}$ or patients with predicted difficult airways. ${ }^{(7)}$ Recently published guidelines from the Difficult Airway Society recommended that all anaesthetists should be trained to use and have immediate access to a videolaryngoscope in the management of unanticipated difficult intubation. ${ }^{(8)}$ A recent editorial in the British Journal of Anaesthesia advocated the routine use of videolaryngoscopes for all tracheal intubations. ${ }^{(9)}$ As such potentially costly equipment may not be readily available in every institution, the frequency of its use has not been widely investigated.

The key to adequate planning is firstly the ability to anticipate a difficult airway. A recent large Danish database study showed that $93 \%$ of difficult intubations were unanticipated..$^{(10)}$ When difficult intubation was anticipated, only $25 \%$ were actually difficult. ${ }^{(10)}$ This demonstrated that the currently available predictors of difficult airway have less than optimal sensitivity, specificity, positive predictive value and negative predictive value. In the study, a large percentage of patients with anticipated difficult airways underwent conventional direct laryngoscopy. ${ }^{(10)}$

We conducted a prospective observational study in a Singapore teaching hospital over a seven-month period. Our aim was to: (a) determine the utility of our routine airway assessment for prediction of difficult tracheal intubation; (b) review the prevailing practice of videolaryngoscope use for tracheal intubation amongst anaesthetists in our hospital; and (c) determine the incidence of intraoperative and postoperative complications with different airway equipment. 


\section{METHODS}

A prospective observational study was undertaken over a sevenmonth period (August 2012-February 2013) of patients undergoing general anaesthesia with endotracheal intubation for elective and emergency surgery, with approval from our institutional ethics board. Patients who were initially planned for a regional anaesthetic or sedation technique were excluded unless they were subsequently converted to general anaesthesia requiring airway management. Patients who entered the operating theatre with an endotracheal tube or tracheostomy in situ were excluded.

Baseline patient characteristics and preoperative assessment details were collected. Airway equipment available in our major operating theatres included the conventional Macintosh laryngoscope, McCoy laryngoscope, C-MAC $($ videolaryngoscope (Karl Storz, Tuttlingen, Germany), GlideScope ${ }^{\circledR}$ (Verathon Medical, Bothell, WA, USA), McGrath $®$ laryngoscope (Aircraft Medical Ltd, Edinburgh, Scotland, UK), Bonfils fibrescope $\mathbb{R}$ (Karl Storz, Tuttlingen, Germany), Pentax airway scope ${ }^{\circledR}$ (AWS; Pentax Corporation, Tokyo, Japan) and the flexible bronchoscope. The C-MAC videolaryngoscope (Fig. 1a) comes in the original Macintosh blade shape or with a more angulated D-Blade and has a flat proximal finish, which enables intubation even in a reduced mouth aperture and avoids damage to incisors. It also has a portable version (Fig. 1b). The GlideScope reusable laryngoscope (Fig. 2) comes with a rigid stylet that complements the angle of the GlideScope. The McGrath laryngoscope (Fig. 3) has a lightweight handle and a Macintosh-type slim profile disposable blade, with a built-in battery that lasts for 250 minutes. The Bonfils fibrescope (Fig. 4) is an intubating endoscope with a metal shaft that has an integrated light and image bundle. The shaft is $35 \mathrm{~cm}$ long, $3.5 \mathrm{~mm}$ or $5 \mathrm{~mm}$ in diameter and angled at $40^{\circ}$ at the distal end. The fibreoptic bronchoscope is a flexible scope that has optical bundles, light bundles and a channel for suction and flushes.

Airway and anaesthetic management was performed the discretion of the attending anaesthetist without any influence from the investigators. Pertinent information regarding airway and anaesthetic management was collected using a data collection form.

Using pre-described predictors ${ }^{(11-13)}$ such as a Mallampati score of 3 or 4 , thyromental distance $<6 \mathrm{~cm}$, inter-incisor gap $<3 \mathrm{~cm}$, limited neck movement, distorted anatomy, history of difficult intubation and unstable cervical spine, the attending anaesthetists
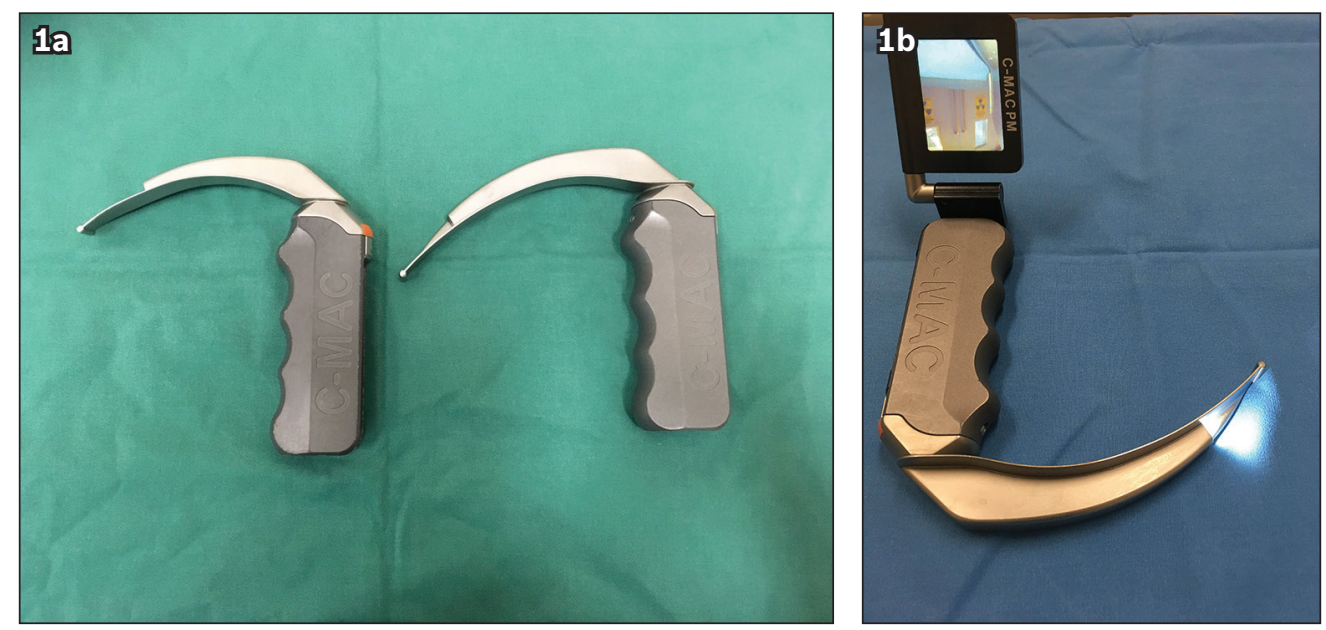

Fig. 1 Photographs show the C-MAC videolaryngoscope, with (a) the original Macintosh blade shape and a flat proximal finish and (b) the portable version.
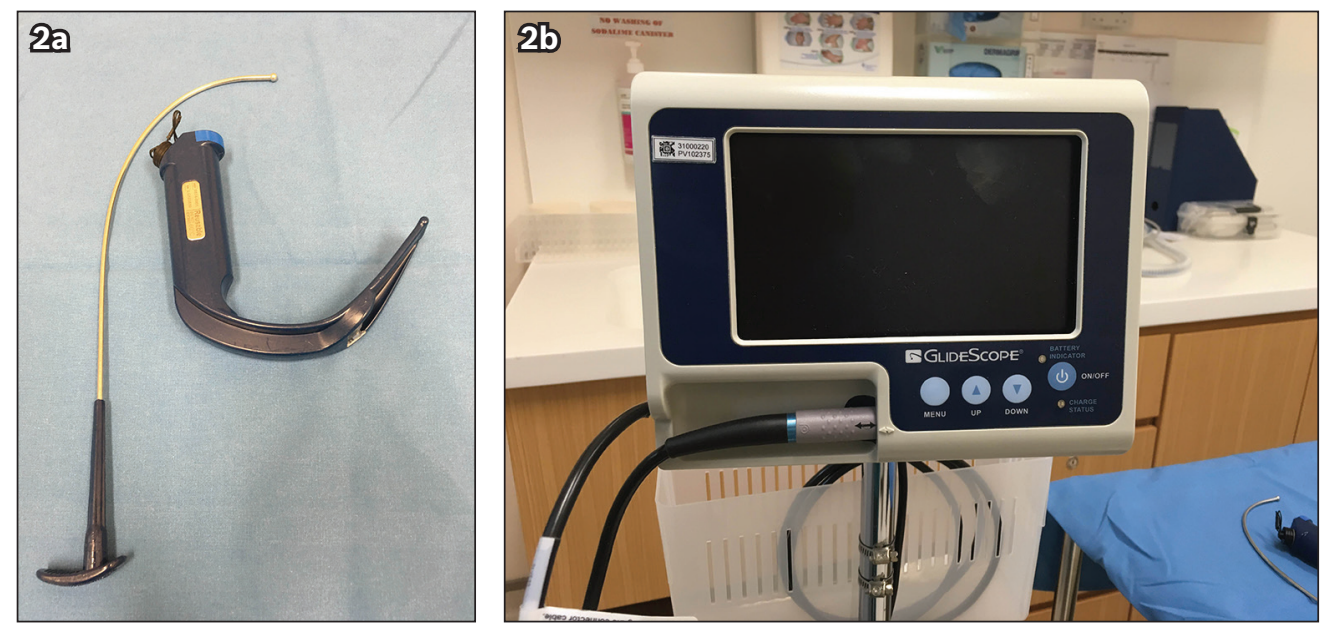

Fig. 2 Photographs show the (a \& b) GlideScope reusable laryngoscopes, which come with a rigid stylet (in a). 


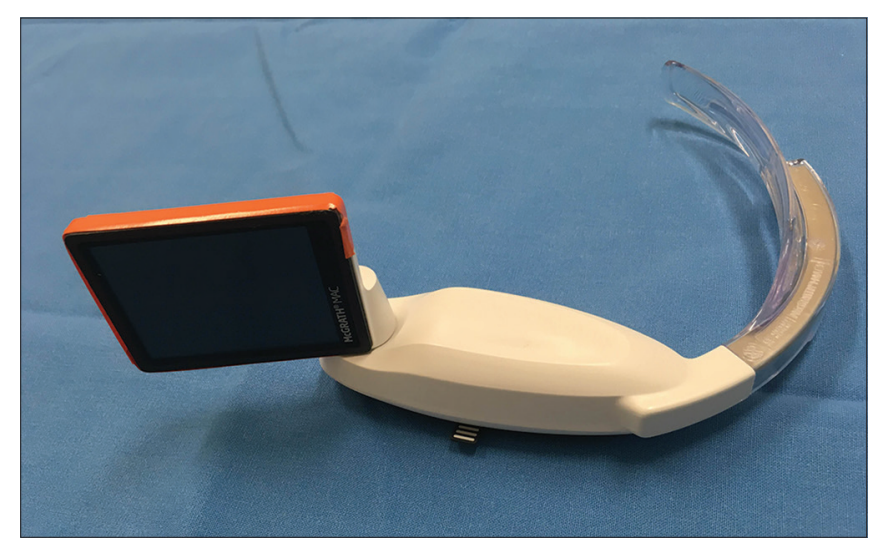

Fig. 3 Photograph shows the McGrath laryngoscope, which has a lightweight handle and a Macintosh-type slim profile with a disposable blade and a built-in battery.

who assessed the airways indicated whether the patients had anticipated difficult intubation. The attending anaesthetists also reported whether the patients were true difficult intubations after airway management. True difficult intubation was defined as proper insertion of the tracheal tube that required more than three attempts or more than ten minutes. ${ }^{(14)}$ Failed intubation was defined as multiple failed attempts by an experienced anaesthetist. ${ }^{(14,15)}$ Intraoperative problems and postoperative complications were recorded by the attending anaesthetists or the nurse-in-charge in the post-anaesthesia care unit.

Data was analysed using STATA 13 (StataCorp, TX, USA) and IBM SPSS Statistics Version 22.0 (IBM Corp, Armonk, NY, USA). Chi-square test was used for categorical variables and Student's $t$-test was used to compare continuous variables. Continuous variables were represented as mean and 95\% confidence intervals, while categorical variables were represented as percentages. The incidences of intraoperative and postoperative complications were coded as composite binary variables. A p-value $<0.05$ was considered statistically significant.

\section{RESULTS}

A total of 1,654 patients underwent general anaesthesia with insertion of endotracheal tubes in the major operating theatre over seven months. For $37.2 \%$ of these patients, the traditional Macintosh laryngoscope was chosen, and for about $60 \%$ of them, the first equipment of choice was a videolaryngoscope such as the C-MAC (36.5\%), GlideScope (20.4\%) or McGrath (3.6\%). The rate of usage of rigid stylet-assisted intubation (Bonfils fibrescope) was $0.7 \%$ and that of flexible bronchoscopic-assisted intubation was $1.6 \%$ (Table I). The baseline characteristics of our study population are summarised in Table II. The most common reason for predicting difficulty in intubation was receding chin (39.4\%), followed by obesity/short neck (24.6\%) and cervical spine problems (18.6\%). Unstable cervical spine, small mouth opening or retropharyngeal abscess were some of the indications for using a fibreoptic bronchoscope as the first equipment of choice. Only one-third of the patients with cervical spine concerns were intubated using a fibreoptic bronchoscope, while the remaining patients underwent videolaryngoscopy.

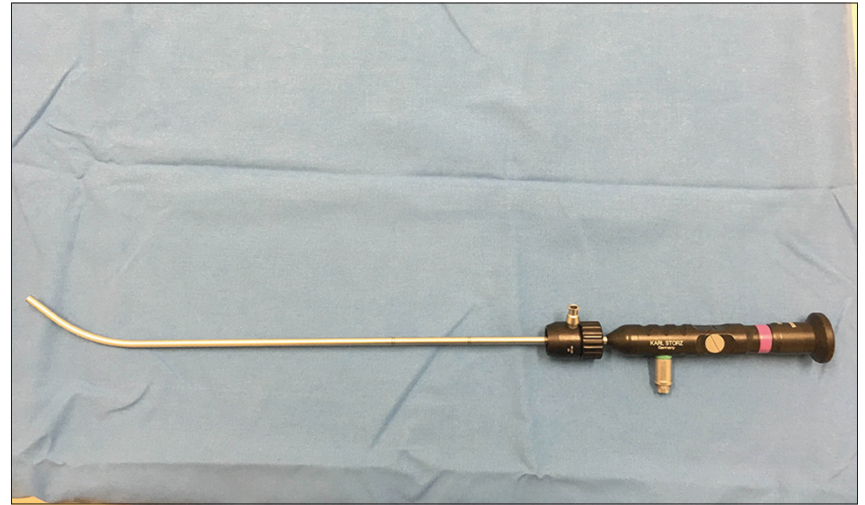

Fig. 4 Photograph shows the Bonfils fibrescope, an intubating endoscope with a metal shaft that has integrated light and image bundle. The shaft is $35 \mathrm{~cm}$ long, $3.5 \mathrm{~mm}$ or $5 \mathrm{~mm}$ in diameter and angled at $40^{\circ}$ at the distal end.

Table I. First equipment of choice for intubation $(n=1,654)$.

\begin{tabular}{lc}
\hline Variable & No. (\%) \\
\hline Macintosh laryngoscope & $615(37.2)$ \\
Videolaryngoscope & $1,001(60.5)$ \\
C-MAC & $604(36.5)$ \\
GlideScope & $338(20.4)$ \\
McGrath & $59(3.6)$ \\
Bonfils fibrescope & $11(0.7)$ \\
Flexible fibreoptic bronchoscope & $27(1.6)$ \\
\hline
\end{tabular}

The incidence of difficult intubation in our study population was $2.1 \%$, and 16 out of the 35 difficult intubations (45.7\%) were unanticipated (Table III). Our assessment of difficult intubation had a sensitivity, specificity, positive predictive value and negative predictive value of $54.3 \%, 86.6 \%, 8.1 \%$ and $98.9 \%$, respectively.

In the 236 patients $(14.3 \%)$ for whom difficult intubation was anticipated, there was an increased use of videolaryngoscopes as the first equipment of choice $(77.1 \%$ vs $13.1 \%, p<0.001$; Table IV). When intubating with the Macintosh compared to all videolaryngoscopes, more patients required a change of airway equipment ( $p=0.015)$, involving a change of blade sizes, the addition of stylets or bougies and frequent changing of the type of laryngoscope. However, the number of intubation attempts were similar $(p=0.293$; Table V).

Intraoperative problems included desaturation, oesophageal intubation, aspiration, bronchospasm, equipment failure, airway trauma, dental trauma and others. Postoperative complications were sore throat, desaturation, hoarseness of voice and airway obstruction in the post-anaesthetic care unit. No emergency airway or failed intubation was reported in the seven-month period. When the Macintosh was compared with all videolaryngoscopes, the incidence of intraoperative problems $(2.0 \%$ vs. $2.5 \%, p=0.920)$ and postoperative complications (5.3\% vs. $7.5 \%, p=0.380$ ) did not show any difference (Fig. 5).

\section{DISCUSSION}

This observational study highlights the current airway management practices in a teaching hospital in Singapore. First of all, we found that the sensitivity of our airway assessment using known 
Table II. Baseline characteristics of study population and comparison between the Macintosh and videolaryngoscope groups.

\begin{tabular}{|c|c|c|c|c|}
\hline \multirow[t]{2}{*}{ Variable } & \multicolumn{3}{|c|}{ No. $(\%) /$ mean \pm SD } & \multirow[t]{2}{*}{ p-value* } \\
\hline & All $(n=1,654)$ & Macintosh $(n=615)$ & Videolaryngoscope $(n=1,001)$ & \\
\hline Age $(y r)^{+}$ & $47.08 \pm 18.07$ & $45.74 \pm 19.24$ & $47.76 \pm 17.32$ & 0.029 \\
\hline Height $(\mathrm{m})^{+}$ & $1.64 \pm 0.09$ & $1.64 \pm 0.09$ & $1.64 \pm 0.09$ & 0.058 \\
\hline Weight (kg)+ & $67.41 \pm 16.07$ & $64.67 \pm 13.20$ & $69.11 \pm 17.39$ & $<0.001$ \\
\hline BMI $\left(\mathrm{kg} / \mathrm{m}^{2}\right)^{+}$ & $25.08 \pm 5.27$ & $24.10 \pm 4.28$ & $25.70 \pm 5.70$ & $<0.001$ \\
\hline 1 & $535(32.3)$ & $241(39.4)$ & 289 (28.9) & \\
\hline 2 & $792(47.9)$ & $289(47.2)$ & $477(47.7)$ & \\
\hline 3 & $300(18.1)$ & $76(12.4)$ & $217(21.7)$ & \\
\hline 4 & $23(1.4)$ & $6(1.0)$ & $17(1.7)$ & \\
\hline Type of surgery & & & & 0.002 \\
\hline Elective $^{\ddagger}$ & $1,018(61.5)$ & $407(66.2)$ & $587(58.6)$ & \\
\hline Emergency & $636(38.5)$ & $208(33.8)$ & $414(41.4)$ & \\
\hline Smoker status ${ }^{*}$ & & & & 0.498 \\
\hline Yes & $318(19.2)$ & $118(19.2)$ & $192(19.2)$ & \\
\hline No & $1,270(76.8)$ & $469(76.3)$ & $775(77.4)$ & \\
\hline Ex-smoker & $66(4.0)$ & $28(4.6)$ & $34(3.4)$ & 0.498 \\
\hline Respiratory condition* & $78(4.7)$ & $30(4.9)$ & $45(4.5)$ & 0.723 \\
\hline
\end{tabular}

Patients intubated with the Bonfils fibrescope $(n=11)$ and flexible fibreoptic bronchoscope $(n=27)$ were excluded from analysis. ${ }^{*} p<0.05$ is considered statistically significant. †Data was analysed using $t$-test. $¥$ Data was analysed using Pearson’s chi-square test. §Missing data for four patients, three in the Macintosh group and one in the videolaryngoscopy group. Percentages were calculated according to the available data. ASA: American Society of Anesthesiology; BMI: body mass index; SD: standard deviation

Table III. No. of patients with anticipated and true difficult intubation.

\begin{tabular}{lccc}
\hline Variable & \multicolumn{2}{c}{$\begin{array}{c}\text { True difficult } \\
\text { intubation }\end{array}$} & Total \\
\cline { 2 - 3 } & Yes & No & \\
\hline Anticipated difficult intubation & & & \\
Yes & 19 & 217 & 236 \\
No & 16 & 1,402 & 1,418 \\
Total & 35 & 1,619 & 1,654 \\
\hline
\end{tabular}

Sensitivity $54.3 \%$, specificity $86.6 \%$, positive predictive value $8.1 \%$, negative predictive value $98.9 \%$.

predictors of difficult intubation was low (54.3\%). ${ }^{(16)}$ About half of the difficult intubations were anticipated and the other half unanticipated. When patients with potential difficult intubation were identified, only $8.1 \%$ were eventually found to be difficult (i.e. positive predictive value). A recent large cohort study also found a positive predictive value of $25 \%$ and that $93 \%$ of difficult intubations were unanticipated (i.e. sensitivity of only $7 \%$ ). ${ }^{(10)} \mathrm{A}$ recent systematic review similarly concluded that current bedside predictors of difficult airway are limited in their discriminative capacity. ${ }^{(16)}$ Our results, which were similar to these studies, reinforced the fact that our ability to anticipate difficult intubations in our local setting is not ideal.

In our institution, a wide range of videolaryngoscopes are readily available, and close to $60 \%$ of the patients were intubated using a videolaryngoscope. This was a prospective observational study that reflects clinical practice in our institution. When difficulty was anticipated, more anaesthetists $(77.1 \%)$ chose a videolaryngoscope as the first choice of equipment rather than a conventional Macintosh laryngoscope. Difficult intubation has been quoted in studies to range from

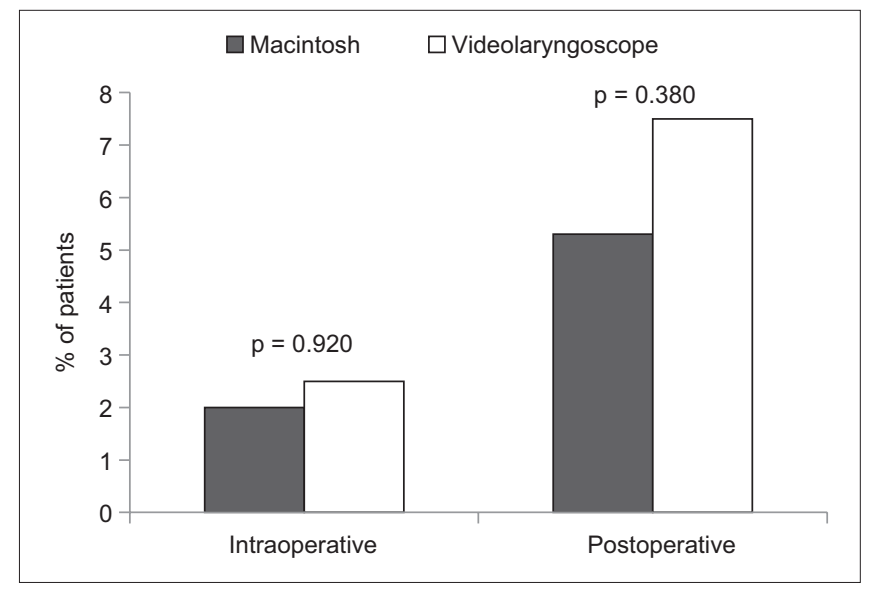

Fig. 5 Bar graph shows the incidence of intraoperative and postoperative complications.

$1.2 \%$ to as high as $5.8 \% .^{(17)}$ It is conceivable that the low percentage of difficult intubation of $2.1 \%$, zero failed intubation and high success rates of intubation at first pass in our study could be due to an increased use of videolaryngoscopes, even in patients with an anticipated normal airway. The unanticipated difficulty in intubation could possibly be circumvented with the use of a videolaryngoscope.

The use of videolaryngoscopes reduced the need for a change of equipment during airway management in our study population. In susceptible patients, a change of equipment resulting in delay in securing a definitive airway may have clinical consequences. This risk is potentially minimised when a videolaryngoscope is the first equipment employed.

Previous studies have suggested that there was insufficient evidence in favour of replacing direct laryngoscopy with 
Table IV. First choice of laryngoscope in anticipated difficult intubation vs. normal airway.

\begin{tabular}{lcc}
\hline Variable & \multicolumn{2}{c}{ No. (\%) } \\
\cline { 2 - 3 } & $\begin{array}{c}\text { Anticipated difficult } \\
\text { airway }(\mathbf{n}=\mathbf{2 3 6})\end{array}$ & $\begin{array}{c}\text { No anticipated difficult } \\
\text { airway }(\mathbf{n}=\mathbf{1 , 4 1 8})\end{array}$ \\
\hline Airway equipment & & \\
Macintosh $(n=615)$ & $31(13.1)$ & $584(41.2)$ \\
Videolaryngoscope $(n=1,001)$ & $182(77.1)$ & $819(57.8)$ \\
Others $(n=38)^{*}$ & $23(9.7)$ & $15(1.1)$ \\
\hline
\end{tabular}

*Includes Bonfils fibrescope and flexible fibreoptic bronchoscope.

Table V. Comparison of insertion attempts and equipment change between Macintosh and videolaryngoscope when chosen as the first choice.

\begin{tabular}{lccc}
\hline Variable & \multicolumn{2}{c}{ No. (\%) } & p-value \\
\cline { 2 - 3 } & $\begin{array}{c}\text { Macintosh } \\
(\mathbf{n}=\mathbf{6 1 5})\end{array}$ & $\begin{array}{c}\text { Videolaryngoscope } \\
(\mathbf{n}=\mathbf{1 , 0 0 1 )}\end{array}$ & \\
\hline Insertion attempt & & & 0.293 \\
1 & $544(88.5)$ & $893(89.2)$ & \\
2 & $69(11.2)$ & $99(9.9)$ & \\
3 & $2(0.3)$ & $9(0.9)$ & $0.015^{+}$ \\
Required change & $39(6.3)$ & $37(3.7)$ & \\
in equipment* & & & \\
\hline
\end{tabular}

Patients intubated using Bonfils fibrescope and flexible fibreoptic bronchoscope were excluded from analysis. *Equipment change involved change of blade sizes, addition of stylet/bougie and change of type of laryngoscope. $+p<0.05$ is considered statistically significant.

videolaryngoscopy in patients with normal or difficult airway. ${ }^{(18,19)}$ Issues relating to $\cos ^{(9)}$ and the resulting deficits in training in direct laryngoscopy and flexible bronchoscopic-assisted intubation ${ }^{(20)}$ were reasons cited for not advocating the routine use of videolaryngoscopy. Videolaryngoscopes have become the popular choice in our institution for anticipated difficult airways, as well as during routine airway management. This was evident in our study, as $57.8 \%$ of patients without an anticipated difficult airway were intubated with a videolaryngoscope as the first choice.

We did not find any statistical difference in intraoperative problems and postoperative complications when comparing conventional Macintosh intubation with the use of videolaryngoscopes. This may have been due to intrinsic differences in patient characteristics that predisposed them to complications. As shown in Table II, patients who had a videolaryngoscope as the first choice were slightly older, had higher body mass index and higher ASA (American Society of Anesthesiologists) status, and were more likely to be undergoing emergency surgery. The increased need for other adjuncts, such as the stylet or bougie, in the videolaryngoscope group may have also increased the risk of complications. Furthermore, videolaryngoscopes were used more frequently in the cohort of patients with anticipated difficult airways ( $<<0.001$, Table IV), who were expected to have a higher risk of airway complications. Overall, the airway complication rate was low in our study and a sample size of 1,654 patients may not be sufficiently powered to detect a difference between the Macintosh and videolaryngoscope groups.
Our study had some limitations. We recognise that as described previously, different videolaryngoscopes may vary in terms of their indications, technical specifications and ease of use, and this study only reflects the practice in a single teaching centre. There are differences in function and utility between the anteriorly angulated, the Macintosh-like and the channelled videolaryngoscopes. The C-MAC videolaryngoscope was probably preferred by anaesthetists in our institution due to its shape and technique of insertion, which is closest to the familiar Macintosh laryngoscope.

Although videolaryngoscopes required fewer changes in equipment, the number of attempts to successful intubation did not differ when they were used, in comparison to the Macintosh laryngoscope. This may suggest that when the initial attempt with a Macintosh laryngoscope failed, a switch to a videolaryngoscope was more likely to occur. However, when there was initial failure with a videolaryngoscope, subsequent attempts with the same equipment were possible with the use of other airway adjuncts such as stylets or bougies.

In conclusion, anaesthetists' detection of a potential difficult airway may influence their choice of laryngoscope, although some use videolaryngoscopes as a first choice without an anticipated difficult airway, suggesting that they view videolaryngoscopy as routine care. This observational study reflects the prevailing practice of videolaryngoscope use in our institution. Further research is required to examine the evolving role of videolaryngoscopes as the standard of care.

\section{ACKNOWLEDGEMENTS}

Data collection forms were collated by the Anaesthesia Unit nurses at Khoo Teck Puat Hospital, Singapore. Data analysis was performed by Ms Su Chang, a biostatistician from the Clinical Research Unit, Khoo Teck Puat Hospital. This study was presented as an e-poster and won the second prize (Audits \& Surveys category) in the World Airway Management Meeting, Dublin, Ireland, in 2015

\section{REFERENCES}

1. Cook TM, Woodall N, Frerk C; Fourth National Audit Project. Major complications of airway management in the UK: results of the Fourth National Audit Project of the Royal College of Anaesthetists and the Difficult Airway Society. Part 1: anaesthesia. Br J Anaesth 2011; 106:617-31.

2. Domino KB, Posner KL, Caplan RA, Cheney FW. Airway injury during anesthesia: a closed claims analysis. Anesthesiology 1999; 91:1703-11.

3. Newland MC, Ellis SJ, Peters KR, et al. Dental injury associated with anesthesia: a report of 161,687 anesthetics given over 14 years. J Clin Anesth 2007; 19:339-45.

4. Pieters BM, Eindhoven GB, Acott C, van Zundert AA. Pioneers of laryngoscopy: indirect, direct and video laryngoscopy. Anaesth Intensive Care 2015; 43 Suppl:4-11. 
5. Cavus E, Thee C, Moeller T, et al. A randomised, controlled crossover comparison of the C-MAC videolaryngoscope with direct laryngoscopy in 150 patients during routine induction of anaesthesia. BMC Anesthesiol 2011; 11:6.

6. Putz L, Dangelser G, Constant B, et al. [Prospective trial comparing Airtraq and Glidescope techniques for intubation of obese patients]. Ann Fr Anesth Reanim 2012; 31:421-6. French.

7. Aziz MF, Dillman D, Fu R, Brambrink AM. Comparative effectiveness of the C-MAC video laryngoscope versus direct laryngoscopy in the setting of the predicted difficult airway. Anesthesiology 2012; 116:629-36.

8. Frerk C, Mitchell VS, McNarry AF, et al; Difficult Airway Society intubation guidelines working group. Difficult Airway Society 2015 guidelines for management of unanticipated difficult intubation in adults. Br J Anaesth 2015; 115:827-48.

9. Zaouter C, Calderon J, Hemmerling TM. Videolaryngoscopy as a new standard of care. Br J Anaesth 2015; 114:181-3.

10. Nørskov AK, Rosenstock CV, Wetterslev J, et al. Diagnostic accuracy of anaesthesiologists' prediction of difficult airway management in daily clinica practice: a cohort study of 188,064 patients registered in the Danish Anaesthesia Database. Anaesthesia 2015; 70:272-81.

11. Wilson ME, Spiegelhalter D, Robertson JA, Lesser P. Predicting difficult intubation. Br J Anaesth 1988; 61:211-6.
12. Arné J, Descoins P, Fusciardi J, et al. Preoperative assessment for difficult intubation in general and ENT surgery: predictive value of a clinical multivariate risk index. Br J Anaesth 1998; 80:140-6.

13. Shiga T, Wajima Z, Inoue $T$, Sakamoto A. Predicting difficult intubation in apparently normal patients: a meta-analysis of bedside screening test performance. Anesthesiology 2005; 103:429-37.

14. American Society of Anesthesiologists Task Force on Management of the Difficult Airway. Practice guidelines for management of the difficult airway: an updated report by the American Society of Anesthesiologists Task Force on Management of the Difficult Airway. Anesthesiology 2003; 98:1269-77.

15. Greenland KB. A proposed model for direct laryngoscopy and tracheal intubation. Anaesthesia 2008; 63:156-61.

16. Vannucci A, Cavallone LF. Bedside predictors of difficult intubation: a systematic review. Minerva Anestesiol 2015; 82:69-83

17. Cattano D, Panicucci E, Paolicchi A, et al. Risk factors assessment of the difficult airway: an italian survey of 1956 patients. Anesth Analg 2004; 99:1774-9.

18. Niforopoulou P, Pantazopoulos I, Demestiha T, Koudouna E, Xanthos T. Videolaryngoscopes in the adult airway management: a topical review of the literature. Acta Anaesthesiol Scand 2010; 54:1050-61.

19. Levitan RM. Video laryngoscopy, regardless of blade shape, still requires a backup plan. Ann Emerg Med 2013; 61:421-2.

20. Dawson SR, Taylor L, Farling P. The true cost of videolaryngoscopy may be trainee experience in fibreoptic intubation. Br J Anaesth 2015; 115:134-5 